\title{
Evaluation of Renewable Energy System For Sustainable Development
}

\author{
Shoeib Faraji Abdolmaleki (D) and Pastora M. Bello Bugallo (D) \\ Department of Chemical Engineering, Universidad de Santiago de Compostela, Av. Lope Gómez de Marzoa, s/n, \\ 15782 Santiago de Compostela, Spain
}

Received: 6 July 2021 / Received in final form: 14 October 2021 / Accepted: 14 October 2021

\begin{abstract}
This study reviews sustainable development (SD) elements through a holistic literature review to consider the relationship between SD indicators in the renewable energy (RE) sector, to identify critical drivers and methodologies needed to solve sustainability problems in RE. Through a systematic review, some compatible articles are selected from the electronic libraries. Driven information is employed to make a database that gives themes, dimensions, and indicators. Afterward, the sustainability evaluation of RE systems is investigated as an objective. Scopes and themes regarding SD and RE are investigated. As a result, SD indicators, RE systems, energy and sustainability, environmental sustainability assessment, energy security, electricity/power production, and energy geopolitics are the most existing scopes. Eleven sustainability frameworks, which scholars have used to consider RE sustainability, are identified appropriately. As a result, key dimensions are environmental, economic, social, technical, and institutional drivers. Therefore, indicators and criteria are reviewed for the top five drivers. Some of the most important of these indicators are: social (acceptability, job creation, social benefit, impact on health), economic (investment cost, operation, maintenance cost, and energy cost), environmental $\left(\mathrm{CO}_{2}\right.$ emission, land use, impact on ecosystem, $\mathrm{NO}_{x}$ and $\mathrm{SO}_{x}$ emissions, GHG emission reduction, particle emission, noise), technical (efficiency, reliability, resource availability, maturity, safety, primary energy ratio, feasibility), and institutional (legal regulation of activity, government support, political stability, absence of violence/terrorism). Also, methodologies are examined to solve the challenge of sustainability evaluation. Literature review, MCDM techniques, LCA, PCA, and statistical methods are among the most widely used. Therefore, fully understanding the evaluation elements of $\mathrm{SD}$ in RE systems and having a database can speed up such studies.
\end{abstract}

\section{Introduction}

Achieving a solution to environmental problems requires long-term potential actions for SD. In this regard, RE resources appear to be one of the most efficient and effective solutions. That is why there is an intimate connection between RE and SD [1]. Also, RE has many advantages over fossil fuels for international security and peace [2]. It is essential for all countries to ensure they have a secure energy supply. It is especially true for European Union (EU) member states because of geopolitical considerations and ongoing reforms of energy markets [3].

The 21st-century economy ties with geopolitics issues and it is not only considered as a one-dimensional topic (i.e., contained income, cost, and interest), but also it faces other definitions such as environmental impact and social effect.

\footnotetext{
* e-mail: shoeib.faraji@rai.usc.es
}

One of the divisions of SD is sustainable energy, which is closely connected with the economy, politics, and environment. Cost reductions in renewables and advances in digital technologies are opening enormous opportunities for the energy transition. Wind and solar photovoltaic $(\mathrm{PV})$ provide more than half of the additional electricity generation to 2040 in the stated policies scenario and almost all the growth in the SD $[4,5]$. Hence, countries tend to apply the integrated concept of SD that could assist their economic policies and decision-making at all levels of the energy sectors [6].

Evaluating the long-term viability of $\mathrm{RE}$ needs a thorough investigation by specialists and academics. When reviewing the literature on sustainable development, it is clear that numerous efforts have been made to assess the long-term viability of processes, industries, regions, and states, among others (e.g., [7-11]). In earlier research, the selection of sustainable development indicators in RE (e.g., $[12-15])$, as well as the application of various methodologies (e.g., $[16,17])$ in solving sustainability measurements, have 
Sustainable development Papers

Employed Paper for Database

Sustainable development $\&$ RE Paper

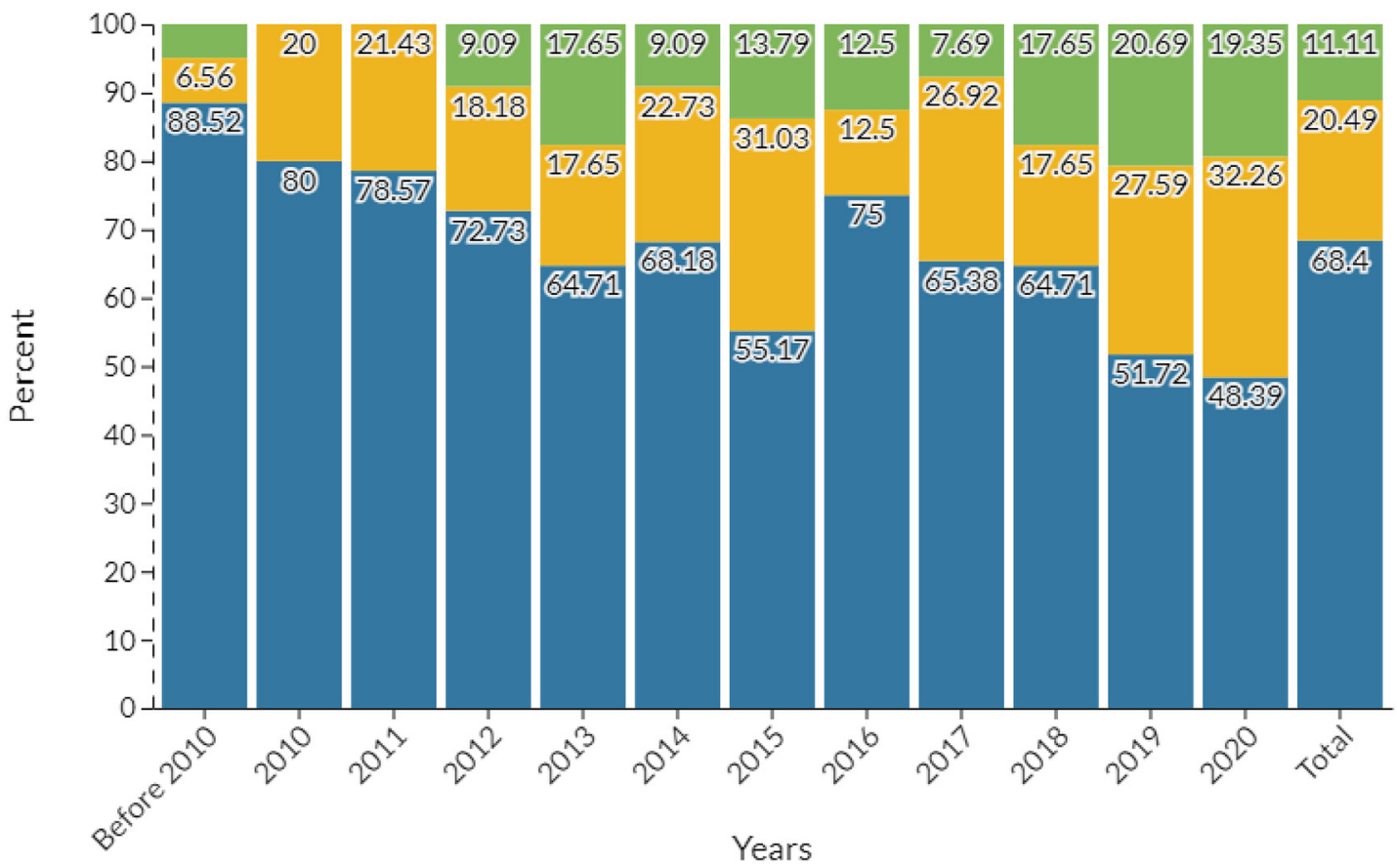

Fig. 1. Percentage of papers selected for study over year.

received a lot of attention. These researches are concentrated on assuring a renewable system's sustainability or analyzing the influence of a renewable system on a specific situation (such as the growth of the economy). In addition, some studies (e.g., $[12,18])$ have looked into the approaches for picking a sustainable development index, as well as its characteristics and measurement techniques. Therefore, it seems that the evaluation of RE systems for SD is essential.

The contribution of this study is to review the literature on sustainability with a focus on renewable systems to recognize the essential SD drivers, to recognize indicators that are necessary for sustainability assessments, and follow approaches for measuring sustainability to clarify the level of renewable systems. To achieve this, in Section 2, material and methods to provide information to conduct this research are studied. In Section 3, the scopes and the scales of the study are examined. Then, in Section 4, elements of SD are explored, such as criteria and indicators for RE sustainability, and the database is considered in the review's framework. Finally, in Sections 5 and 6 , the study is discussed and concluded.

\section{Material and methods}

The material of the study comprises articles published from 1994 to 2020 in international peer-reviewed scientific journals focused on SD indicators and RE (Fig. 1). Papers gather up with a systematic literature review on some scientific platforms (Fig. 2).
In the literature review, a special aim is to focus on RE while SD indicators are also considered when the contents of the papers seemed to be relevant to the objectives of this study. Empirical research related to sustainability measurement within these fields is also included. Regarding the conceptual tools of sustainability evaluation, information on criteria and indicators is a crucial concern in the literature searches compared to information on principles and verifiers. Also, it is assumed to provide more operational and meaningful principles with high generality strong contextdependent specificity.

So, the current systematic literature review of this study is comprised by three steps:

- Step 1: the searching process is based on Scopus to seek articles relevant from the perspective of this study.

- Step 2: the abstracts of the articles identified in step 1 are entirely examined to select studies for further scanning in step 3. To avoid selection influence resulting from excessive selection procedure, all abstracts with even weak relevance from the perspective of this study are selected for step 3 .

- Step 3: the entire contents of the articles chosen in step 2 are studied to determine the initial set of articles for the material of this study.

In the first step, several keywords are employed as a combination of dual, triple, and quadruple (e.g., SD, sustainability of RE, SD indicator, etc.). Then the name of the article, journal, electronic database, and other information related to the article are collected. 


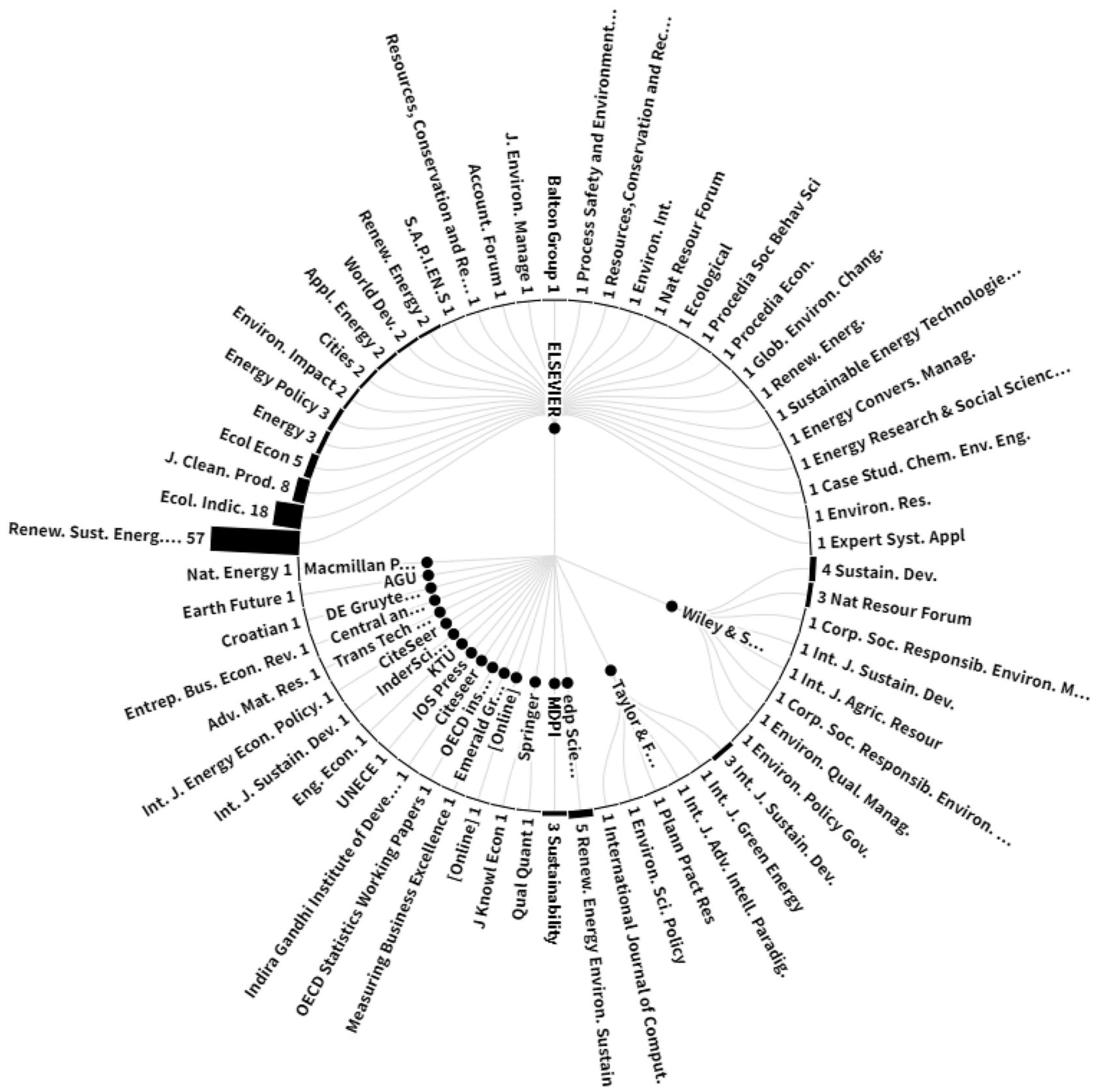

Fig. 2. Radial hierarchy visualization of the papers used for making database.

\section{Scopes of the articles}

In general, the thematic orientation of the articles is examined (Fig. 3). The percentage of these orientations (given the frequency of their distribution) are included: SD indicators, SD in RE, SD definitions, renewable systems, energy and sustainability, environmentally sustainability assessment, energy security, energy systems, electricity/ power production, and geopolitics respectively. In terms of study scales, the focus of most studies was on a global scale which included the EU was followed by Asia. Moreover, some articles were about America and Africa, and only a few studies were examined on small scale.

\section{Elements of sustainable development evaluation}

In this section, topics to consider SD frameworks and policies, dimensions, indicators, and criteria are included to see what elements of SD should be 


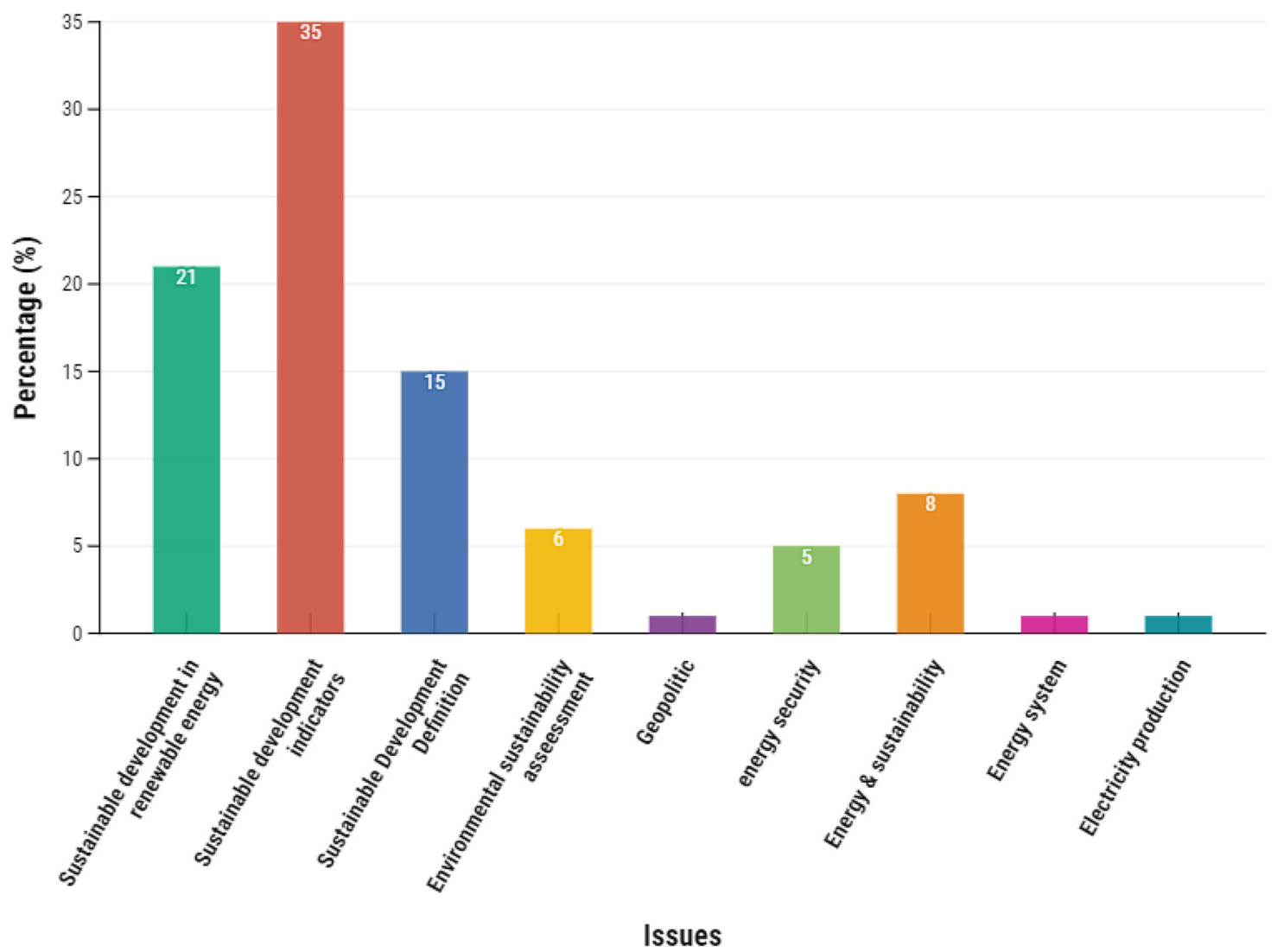

Fig. 3. Scope of the articles.

determined. For an integrated investigation, information is compiled, and materials are recognized. Consequently, key drivers and relevant indicators are studied carefully.

\subsection{Key drivers}

SD evaluation of a system requires the joint work of scientists and politicians in many different fields. Rametsteiner et al. (2011) believe that "the development of sustainability indicators is a process of both scientific knowledge production and political norm creation, and both components need to be properly acknowledged" [19]. Furthermore, these policies and communications show that the concept of RE is essential in EU policy, as an example, and that the EU is strongly committed to promoting RE.

Frameworks are the logical structures over which the indicators are developed [20]. A framework serves as a highlevel, direct reference to the basic concepts of SD [21]. RE has become a dominant concept in energy policy, and many national-international legal frameworks are specifically designed around the idea of classifying energy sources as renewable or non-renewable.

Therefore, drivers can be identified by selecting a framework to solve the sustainability evaluation in a renewable system. Sustainability is most often defined as meeting the needs of the present without compromising the ability of future generations to meet theirs. It has three main pillars: economic, environmental, and social. These three pillars are stated like people, planet, and profits. However, each study based on its nature may have its drivers.

\subsection{Essential indicators and criteria to evaluate sustainability of RE}

Many RE sources such as geothermal, solar, wind, renewable fuels including those from waste, are used over the world, because of their advantages of less emission, less pollution, clean, and less fossil fuel resources usage. It is also indicating $\mathrm{RE}$ and SD have such a close relationship [22].

Inclusive sustainability indicators must supply the numerical value of the sustainability result and the results of all the dimensions of system sustainability so that the users can link systems sustainability and select the highest sustainability with the lowest costs. The users must conclude if the benefit of a RE system exceeds its costs and if it is more attractive than other systems. A numerical value helps simplify their assessment and decision-making [13].

\section{Results and discussion}

\subsection{Frameworks, drivers, and indicators}

Widespread frameworks have been reviewed extensively on a local, national, and international scale in which scholars have focused on the issue of SD from a specific perspective. 
Table 1. Elements of renewable energy sustainability evaluation.

\begin{tabular}{lc}
\hline Dimensions of the Sustainable Development & Percent $(\%)$ \\
\hline Environmental-Economical-Social & 61 \\
Environmental- Economic- Social- Technical & 12 \\
Environmental-Economic-Social-Technical-Institutional & 5 \\
Environmental-Economic-Energy supply & 1 \\
Environmental-Economic-Technical- institutions & 1 \\
Economic & 3 \\
Environmental-Economic & 1 \\
Energy supply & 3 \\
Environmental & 5 \\
Environmental-Economic-Political- Energy supply & 2 \\
Environmental- Economic-Social- Energy supply & 1 \\
Energy supply & 4 \\
Social & 1 \\
\hline
\end{tabular}

In fact, their viewpoints cause them to select a conceptual framework to assess the sustainability of RE. Some of the most preferred frameworks are capital accounting, capitalbased, national accounts, causal framework, issued-based framework, systems-based, sectorial or domain, black box, a roundtable on sustainable biomaterial, Triple Bottom Line (TBL), and 3E System.

Drivers of SD in each article are identified precisely. Therefore, thirteen groups of elements are investigated (Tab. 1). Many articles widely employed "environmentaleconomic- social" together in their framework to consider sustainability as a matter of an energy system, which is highly related to the scope of the study.

Table 1 indicates the most studied dimensions of the SD to measure the sustainability of RE. Generally, the drivers following social, economic, environmental, technical, and institutional (governmental) aspects. Also, some components like energy and political consideration of a system have been recognized as elements for evaluations. Relating to RE, aside from the three main pillars, technical and institutional drivers have become very important recently.

Regarding RE, issues like electricity production, investment in a project, technology, and resources, are some major literature that has tied with SD purposefully. For example, the authors of papers [23-25] have considered indicators related to RE development. Some references (e.g., [13,2630]) have studied RE system assessment indicators and criteria related to this system. Also, the works such as $[25,31,32]$ have carried out a comprehensive study in frameworks for energy project indicators. Besides, some other scholars (e.g., $[18,33]$ ) have recognized indicators related to electricity production and power systems. Moreover, the works of [34] and [35] have applied indicators to assess RE in energy supply security. Also, a bunch of articles have been discussed the sustainable indicators based on various frameworks and criteria (e.g., [27,36-39]).

However, frameworks, drivers, and scopes of RE sustainability consideration have a variety. Social, economic, environmental, technical, and institutional indicators are drawn from the available literature. As a result, this study proposes the most utilized indicators in RE sustainability assessment for each driver:

- Social indicator set: social acceptability, job creation, social benefit, impact on health, compatibility with political and legislative situation international obligation, public awareness and willingness, availability, and R\&D.

- Economic indicator set: investment cost, operation and maintenance cost, energy cost, fuel cost, payback period, net present value, service life, cost of capital, generation cost per unit, GDP, and employment rate.

- Environmental indicator set: $\mathrm{CO}_{2}$ emission, land use, impact on ecosystem, $\mathrm{NO}_{\mathrm{x}}$, and $\mathrm{SO}_{x}$ emission, GHG emission reduction, particle emission, noise, need for waste disposal, and emission generally.

- Technical indicator set: efficiency, reliability, resource availability, maturity, safety, primary energy ratio, feasibility, continuity and predictability of performance, capacity factor, and innovativeness.

- Institutional indicator set: the legal regulation of activity, government support, political stability, absence of violence/terrorism, control of corruption, the efficiency of subsidy for the feed-in tariff, compliance with international obligations, and influence on SD of energy.

In SD, the United Nations (UN) has presented various goals on different issues, known as 17 SDGs. Goals are global development targets that were adopted in September 2015 and are expected to be met by 2030. The world's countries have decided to work together to achieve these goals, which are outlined in a list of 169 SDG targets with 232 distinct indicators that have been agreed upon to track progress toward these goals [40].

In comparison with the indicators obtained from this study and the list of these indicators provided by the UN [41], it is possible to achieve that some indicators intended to assess the sustainability of renewables are directly related. 
Table 2. Comparison direct relationship between UN sustainable indicators towards RE evaluation.

\begin{tabular}{|c|c|c|c|}
\hline Indicator & SDG & Definition & Dimension \\
\hline Job creation & 8.3 .1 & $\begin{array}{l}\text { Proportion of informal employment in total } \\
\text { employment, by sector and sex }\end{array}$ & \\
\hline Unemployment rate & 8.5 .2 & $\begin{array}{l}\text { Unemployment rate, by sex, age and } \\
\text { persons with disabilities }\end{array}$ & Social \\
\hline $\mathrm{CO}_{2}$ emission & 9.4 .1 & $\mathrm{CO}_{2}$ emission per unit of value added & \\
\hline GHG emission reduction & 13.2 .2 & Total greenhouse gas emissions per year & \\
\hline $\begin{array}{l}\text { Maintain ecosystem } \\
\text { (impact on ecosystem) }\end{array}$ & $\begin{array}{l}2.4,6.6,6.6 .1,14.2 \\
15.1 .2,15.4,15.8 \\
15.9,15 . \mathrm{a}\end{array}$ & $\begin{array}{l}\text { A measure of renewables impact on the } \\
\text { environment, visual appeal, and } \\
\text { biodiversity }\end{array}$ & Environmental \\
\hline Energy efficiency & 7.3 & Improvement in energy efficiency & \\
\hline Capacity & 7.b.1 & $\begin{array}{l}\text { Installed renewable energy-generating } \\
\text { capacity in developing countries (in watts } \\
\text { per capita) }\end{array}$ & Technical \\
\hline $\begin{array}{l}\text { Reduce all forms of } \\
\text { violence }\end{array}$ & 16.1 & $\begin{array}{l}\text { Significantly reduce all forms of violence } \\
\text { and related death rates everywhere }\end{array}$ & \\
\hline Control of corruption & 16.5 & $\begin{array}{l}\text { Substantially reduce corruption and } \\
\text { bribery in all their forms }\end{array}$ & \\
\hline $\begin{array}{l}\text { Compliance with } \\
\text { international obligations }\end{array}$ & 12.4 .1 & $\begin{array}{l}\text { The number of parties to international } \\
\text { multilateral environmental agreements on } \\
\text { hazardous waste and other substances who } \\
\text { fulfill their pledges and obligations in terms } \\
\text { of submitting information as needed by } \\
\text { each agreement }\end{array}$ & Institutional \\
\hline
\end{tabular}

"Energy efficiency" and "capacity" are two illustrative indicators to ensure access to affordable, reliable, sustainable, and modern energy for all. As we know, SDG7 has a very good overlap with RE. A closer look reveals that in addition to SDG7, there are other goals involved in investigating the sustainability of RE, both directly and indirectly. Table 2 lists the RE evaluation indicators that are directly related to the UN SDGs.

For example, to promote inclusive and sustainable economic growth, full and productive employment and decent work for all (SDG8), the "proportion of employment" (SDG8.3.1) is frequently used as an indicator in the RE section. The "unemployment rate", by sex, age, and persons with disabilities (SDG8.5.2) is another social indicator that commonly is employed to evaluate $\mathrm{RE}$ sustainability.

" $\mathrm{CO}_{2}$ emission", "GHG emission reduction", and "maintain ecosystem" (impact on the ecosystem) are three environmental indices that regularly are utilized in this literature. In RE sustainability assessment, $\mathrm{CO}_{2}$ emission has been applied in different units or definitions. For example, Kourkoumpas et al. (2018) hired a reduction of the direct $\mathrm{CO}_{2}$ emissions and $\mathrm{CO}_{2}$ equivalent payback time [42]. On the contrary, Pratama et al. (2017) investigated the $\mathrm{CO}_{2}$ intensity of electricity and the $\mathrm{CO}_{2}$ intensity of the economy for sustainability assessment [43]. Regarding goal $9, \mathrm{CO}_{2}$ emission per unit is examined towards building resilient infrastructure, promote inclusive and sustainable industrialization, and foster innovation that remarkably used in RE sustainability evaluation (e.g., [42,44-47]). To take urgent action to combat climate change and its impacts (SDG13), the UN has decided to strengthen resilience, adapt capacity to climate-related hazards and natural disasters in all countries. Besides, it incorporates climate change policies, strategies, and planning into national policies, strategies, and planning in which total greenhouse gas emissions per year consider as an indicator.

In addition, "Impact on ecosystem" appears frequently in some of SDGs. Goal 2 is concerned about ensuring sustainable food production systems by 2030 and implement resilient agricultural practices that increase productivity and production to end hunger, achieve food security and improved nutrition, and promote sustainable agriculture. Also helping to maintain ecosystems, strengthening capacity for adaptation to climate change, extreme weather, drought, flooding, and other disasters, and gradually improving land and soil quality, are counted as other impacts on the ecosystem. Furthermore, SDG6 follows ensuring the availability and sustainable management of water and sanitation for all in which protecting and restoring water-related ecosystems, including mountains, forests, wetlands, rivers, aquifers, and lakes are such attentions. Therefore, RE (especially bioenergy due to being water consuming plant) can impact the ecosystem by changing the extent of waterrelated over time or entering effluent. Moreover, SDG (14 and 15) can be connected to RE evaluation since they are interested in preventing marine resources (SDG14) and protecting the application of terrestrial ecosystems, forests management, combat desertification, halt land degradation, and halt biodiversity loss (SDG15). 
"Compliance with international obligations" examines how the national energy strategy and the proposed RE alternative are integrated. It assesses the degree to which the government's policy and the suggested policy have similar goals. The criterion also considers the government's backing, institutional actors' tendencies, and public information policy [44,48-50]. It is under goal 12 to ensure sustainable consumption and production patterns. "Reduce all forms of violence" and "control of corruption" following significant reduce violence and related death rates everywhere and reduce corruption and bribery in all forms that are used to support SDG 16, which are seen in RE literature.

\subsection{Methods of sustainability assessment}

Since evaluating the SD of RE has different variables, the researcher's effort is oriented to properly examine the effects of these variables on the targets by selecting capable sets of criteria and factors. Thus, sustainability assessment becomes a multivariate or multi-objective issue. Generally, solving a multi-objective/multivariable problem depends on the scholars' or experts' standpoints. Projects may be carried out by maximizing the strength of relationships between variables or evaluated by eliminating negative elements to improve assessment quality.

The features of a RE system are scored and analyzed with the concept of ranking. In this situation, analytical, statistical, or hybrid processing are used to assess and rank the RE whit criteria and factors' weight, as well as their importance in the data series (parameters). Therefore, the sustainability evaluation of renewable systems is assessed or predicted dynamically or statically by applying the input data panel (criteria and factors). Despite various mathematical algorithms and computational technology, solving such problems and optimization perspectives seems easy [51].

In energy debates, several software tools are developed by energy professionals, engineers, and thinkers. Therefore, designing energy systems and analyzing multi-criteria systems would be performed at considerable speed. Furthermore, a combination of mathematical methods increases the analytical power in the pre-processing and post-processing stages. Besides, the recent software development that has been sophisticated to be used by energy planners with scarce skills, is helped energy professionals with the processes of hybrid RE systems planning and design without being worried about the underlying mathematics [44,52].

Figure 4 shows the most utilized methodology through sustainability assessment of RE. The pie diagram gives information about the frequency of the methods to evaluate the sustainability of RE. Also, it demonstrates the topics concerning sustainability evaluation in RE, which is shown in the middle section of the diagram, and the outer section shows dependent methodologies. Thus, a variety of issues related to the sustainability of renewables are evaluated, such as power generation, technology and energy planning, investment, finding key performance indicators, system assessment, RE sources, the impact of RE on SD, and assessing the sustainability of RE comprehensively.
Considerably, most of the scholars used literature review and expert view point for sustainability evaluation. Besides, Multi-Criteria-Decision-Making (MCDM) (53.7\%), Combination methods (18.5\%), statistical approaches (14.81\%), Principal Component Analysis (PCA) (5.57\%), and Life Cycle Analysis (LCA) (3.7\%) are mostly employed to assess the sustainability of renewables over time.

For instant, authors like as $[31,53,54]$ have applied literature review to choose an appropriate framework to evaluate the sustainability of energy projects. Also, [25,55] have considered development in renewables, and reference [48] measured sustainable energy systems by using a literature review. Moreover, to classify and assess indicators, authors in works $[13,14,39,56]$ have employed literature review. Expert viewpoint, as a fruitful approach was performed for weighting indicators in indicator panels to realize which indicator has more effect in the evaluation. In addition, to select a set of sustainable urban development indicators, to assess the sustainability of energy technologies via social indicators, and to choose SD indicators for the transmission system of an electric utility all used elite and expert viewpoints to develop their study.

MCDM has widely gained methods in terms of evaluating and assessing sustainability of renewable technology, renewable system assessment, and other assessments like environmental and energy sustainability. It is worth noting that the evaluation of RE projects and RE technology and energy planning used solely the MCDM technique. They not only consider many concepts such as environmental, economic, social, technological, and political, but they are also suitable tools for those who use decision criteria to process the relationship between variables and prospects. Furthermore, these techniques are widely used to manage various, competing criteria to get superior results [57].

LCA is employed predominantly to evaluate the sustainability of RE technologies and to obtain critical indicators of sustainability for biofuels [58]. However, due to its weaknesses in the framework cannot be employed in sustainability evaluation alone because the current structure of the LCA only allows identifying and quantifying environmental indicators, but the combination of LCA with a method such as MCDM make it strengthened so it can evaluate the main dimensions of sustainable development quantitatively and descriptively [59]. The results present that LCA mostly is considered in assessing the sustainability of RE and RE Technology \& Systems assessment.

PCA is frequently applied for electricity and power generation from renewable systems and to evaluate the general sustainability of RE. It is a method for lowering dataset dimensionality, improving interpretability, and minimizing information loss. So it is widely adopted to create an RE sustainable index. For example, Wang et al. (2020) applied dynamic principal component analysis (DPCA) twice to calculate the overall score for development in the RE industry in China. First, to generate a single index for each of the five selected dimensions of RE development, and second, to combine these five indices into 


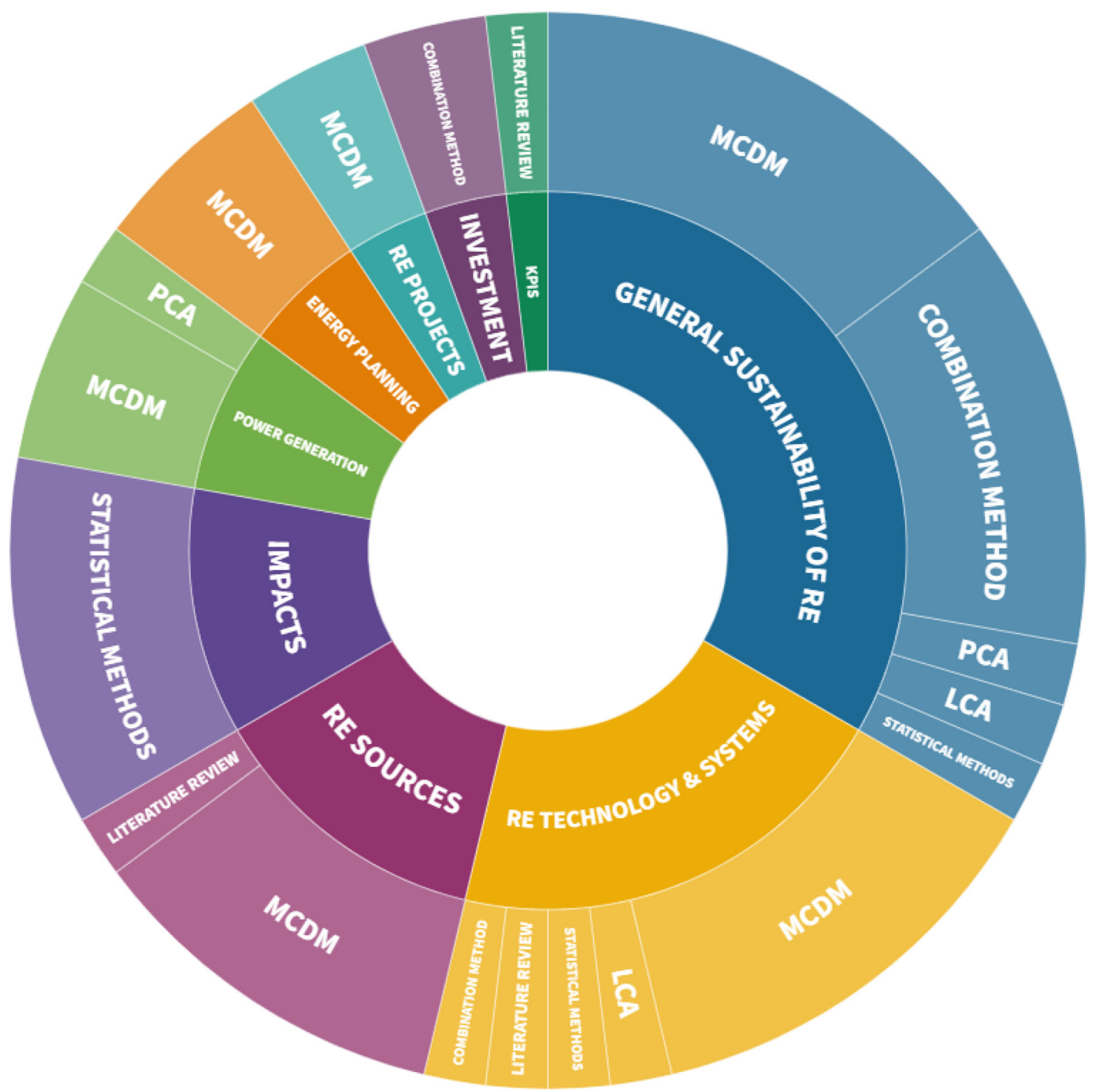

Fig. 4. Most used methodology to study sustainable development evaluation in RE.

an overall index of RE development, which eventually scored for each province of China were standardized between one and five [23].

Combined methods, which are the application of some methods in SD, regularly are used to determine a better perception of the sustainability level of RE systems for technology assessment and investment. Combination methods are recognized as the second preferred method that has solved the evaluation problem by combining two or more methodologies. These methods have widely participated in assessing sustainability of RE. Also, regarding the literature, only this method has been used in RE investment evaluation, which has been a combination of MCDM, statistical methods, LCA, and other decision support methods.

When examining the impact of RE on SD, scholars have focused on statistical methodologies, and are also extensively have employed for RE technology assess- ment. Shahbaz et al. (2020), to investigate the sustainability of RE in EU countries employed a fuzzy clustering model and accelerated genetic algorithm [60]. Furthermore, cluster analysis was employed to evaluate SD management in EU countries [61]. Matsumoto et al. (2016) used time-series clustering techniques to examine energy security performance in EU countries [3]. Tran (2016), to select a set of sustainable urban development indicators adopted variable clustering analysis with an interactive method [62]. They were some instances of using clustering methods through the literature review.

Although several methods exist to evaluate, assess, and consider SD progress in different themes, these methods have their pros and cons, advantages and disadvantages, negatives and positives that we should consider before employing them to recognize whether they are appropriate or not. 


\section{Conclusion}

$\mathrm{SD}$ is an open-end definition, and the assessment and conducting of a unique study need its frameworks. These frameworks should be made from goals, policies, and factors, which political actors and scientists are considered to develop frameworks simultaneously to evaluate SD in various scales. This article provides a complete description of the elements of the RE evaluation for SD. This study was able to signify information regarding the frameworks, indicators, procedures, and objectives of sustainability evaluation by using a systematic approach and establishing an applicable database. As a result, the sustainability scopes, drivers and dimensions, and a set of essential indicators are identified. Several associated articles in SD indicators and SD assessments in the RE sector were selected and studied through scientific platforms.

Pillars of SD include the environment, economy, and society. However, other studies have found that, in addition to these pillars, there are other factors to consider, such as technical, institutional, and physical sustainability. Then, the study is followed by the indicators that have been engaged in each driver, still, the three main dimensions have been the most employed indicators (environmental, economic, and social). Consequently, the most considerable indicators in each driver can be named as follows: social (social acceptability, job creation, social benefit, impact on health, compatibility with political and legislative situation international obligation, public awareness and willingness, availability, and R\&D government support), economic (investment cost, operation and maintenance cost, energy cost, fuel cost, payback period, net present value, service life, cost of capital, generation cost per unit, GDP, and employment rate), environmental $\left(\mathrm{CO}_{2}\right.$ emission, land use, impact on ecosystem, $\mathrm{NO}_{x}$, and $\mathrm{SO}_{x}$ emission, $\mathrm{GHG}$ emission reduction, particle emission, noise, need for waste disposal, and emission generally), Technical (efficiency, reliability, resource availability, maturity, safety, primary energy ratio, feasibility, continuity and predictability of performance, capacity factor, and innovativeness), and Institutional (the legal regulation of activity, government support, political stability, absence of violence/terrorism, control of corruption, the efficiency of subsidy for the feedin tariff, compliance with international obligations, and influence on SD of energy). The range of indicators is such that specialized frameworks must be created by the scopes of research to select an acceptable indicator or group of indicators. Therefore, determining the proper framework can gain the results obtained from the selection of indicators.

In addition, there are numerous ways for assessing $\mathrm{RE}$ sustainability that not only quantify the degree of sustainability but also evaluate the impact of renewable systems for a certain driver. MCDM, combination methods, LCA, PCA, statistical approaches, and literature review are considered pioneering techniques. According to this, MCDM methods are powerful tools to measure the level of sustainability in RE. To better evaluate, combination methods scored second place of utilization among all. Furthermore, the importance of using different methods is evaluated by thematic evaluation of the sustainability assessment of renewable systems. The results show that MCDM methods are leading in the analysis of projects and planning for renewable structures.

This paper suggests exploring the relationship between SD elements using graphical techniques, conditional probabilities, and rule creation for further studies. Also, it is anticipated that defining fitted guidelines may speed up the study of sustainability evaluation in RE systems.

\section{Implementations and influences}

This study follows the sustainability assessment of RE to realize patterns existing towards SD. It takes a comprehensive look at all aspects of SD in RE and expresses the assessment methods, indicators, and the interrelationships between the existing components with different scopes. The direction of this study will help those looking for indicators to assess RE sustainability.

\section{Declaration of competing interest}

The authors declare that they have no known competing financial interests or personal relationships that could have appeared to influence the work reported in this paper.

\section{References}

1. I. Dincer, Renewable energy and sustainable development: a crucial review, Renew. Sustain. Energy Rev. 4, 157-175 (2000)

2. R. Vakulchuk, I. Overland, D. Scholten, Renewable energy and geopolitics: A review, Renew. Sustain. Energy Rev. 122, $109547(2020)$

3. K. Matsumoto, M. Doumpos, K. Andriosopoulos, Historical energy security performance in EU countries, Renew. Sustain. Energy Rev. 82, 1737-1748 (2016)

4. International Energy Agency, Indicators of Energy Use and Efficiency Understanding the Link between Energy and Human Activity. Paris: OECD Publishing, 1997

5. International Energy Agency, The link between energy and human activity [electronic resource]/ IEA. Paris: OECD Publishing, 1998

6. P.G. Taylor, K. Abdalla, R. Quadrelli, I. Vera, Better energy indicators for sustainable development, Nat. Energy. 2, 1-4 (2017)

7. A. Sayigh, Up-date: Renewable energy and climate change, Renew. Energy Environ. Sustain. 6, 13 (2021)

8. C. Malamatenios, Renewable energy sources: Jobs created, skills required (and identified gaps), education and training, Renew. Energy Environ. Sustain. 1, 23 (2016)

9. Y. Anker, D. Mualem, H. Langstadter, F. Nakonechny, M. Nisnevitch, Integrative approach for wastewater treatment facilities with biomass transformation into energy, Renew. Energy Environ. Sustain. 2, 6 (2017)

10. T. Wang, W. Cheng, Research on frame system for sustainable development of rural construction in cold regions based on green concept, Renew. Energy Environ. Sustain. 1, 19 (2016) 
11. R. Madriz-Vargas, A. Bruce, M. Watt, L.G. Mogollón, H.R. Álvarez, Community renewable energy in Panama: a sustainability assessment of the 'Boca de Lura' PV-WindBattery hybrid power system, Renew. Energy Environ. Sustain. 2, 18 (2017)

12. C. Ghenai, M. Albawab, M. Bettayeb, Sustainability indicators for renewable energy systems using multi-criteria decision-making model and extended SWARA/ARAS hybrid method, Renew. Energy 146, 580-597 (2020)

13. G. Liu, Development of a general sustainability indicator for renewable energy systems: A review, Renew. Sustain. Energy Rev. 31, 611-621 (2014)

14. E. Heylen, G. Deconinck, D. Van Hertem, Review and classification of reliability indicators for power systems with a high share of renewable energy sources, Renew. Sustain. Energy Rev. 97, 554-568 (2018)

15. M. Colla, A. Ioannou, G. Falcone, Critical review of competitiveness indicators for energy projects, Renew. Sustain. Energy Rev. 125, 109794 (2020)

16. A. Mardani, A. Jusoh, E.K. Zavadskas, F. Cavallaro, Z. Khalifah, Sustainable and renewable Energy: an overview of the application of multiple criteria decision making techniques and approaches, Sustainable 7, 13947-13984 (2015)

17. A. Kumar et al., A review of multi criteria decision making (MCDM) towards sustainable renewable energy development, Renew. Sustain. Energy Rev. 69, 596-609 (2017)

18. B. Wang, Q. Wang, Y.M. Wei, Z.P. Li, Role of renewable energy in China's energy security and climate change mitigation: an index decomposition analysis, Renew. Sustain. Energy Rev. 90, 187-194 (2018)

19. E. Rametsteiner, H. Pülzl, J. Alkan-Olsson, P. Frederiksen, Sustainability indicator development-science or political negotiation?, Ecol. Indic. 11, 61-70 (2011)

20. H.S. Kristle Nathan, B. Sudhakara Reddy, A conceptual framework for development of sustainable development indicators, Indira Gandhi Institute of Development Research Mumbai, 2008

21. L. Pintér, P. Hardi, P. Bartelmus, Sustainable development indicators: proposals for the way forward, Int. Inst. Sustain. Dev. 1-35 (2005)

22. G. Mitchell, A. May, A. McDonald, PICABUE: a methodological framework for the development of indicators of sustainable development, Int. J. Sustain. Dev. World Ecol. 2, 104-123 (1995)

23. Y. Wang, D. Zhang, Q. Ji, X. Shi, Regional renewable energy development in China: A multidimensional assessment, Renew. Sustain. Energy Rev. 124, 109797 (2020)

24. M. Papież, S. Śmiech, K. Frodyma, Determinants of renewable energy development in the EU countries. A 20-year perspective, Renew. Sustain. Energy Rev. 91, 918-934 (2018)

25. L. Xu, X. Fan, W. Wang, L. Xu, Y. Duan, R. Shi, Renewable and sustainable energy of Xinjiang and development strategy of node areas in the 'Silk Road Economic Belt,' Renew. Sustain. Energy Rev. 79, 274-285 (2017)

26. B. Kuleli Pak, Y.E. Albayrak, Y.C. Erensal, Renewable energy perspective for Turkey using sustainability indicators, Int. J. Comput. Intell. Syst. 8, 187-197 (2015)

27. V. Cornescua, R. Adam, Considerations regarding the role of indicators used in the analysis and assessment of sustainable development in the E.U, Proc. Econ. Financ. 8, 10-16 (2014)
28. O. Demirtas, Evaluating the best renewable energy technology for sustainable energy planning, Int. J. Energy Econ. Policy. 3, 23-33 (2013)

29. J.C. Mourmouris, C. Potolias, A multi-criteria methodology for energy planning and developing renewable energy sources at a regional level: a case study Thassos, Greece, Energy Policy 52, 522-530 (2013)

30. C.Y. Diao, J.F. Li, Research on sustainable development mechanism of renewable energy using system theory, Adv. Mater. Res. 779, 1320-1323 (2013)

31. I. Khan, F. Hou, A. Zakari, V.K. Tawiah, The dynamic links among energy transitions, energy consumption, and sustainable economic growth: A novel framework for IEA countries, Energy. 222, 119935 (2021)

32. R.P. Dhital, P. Pyakurel, T.R. Bajracharya, R. Shrestha, Framework for sustainability assessment of renewable energy projects in Nepal, Int. J. Anal. Hierarchy Process. 6, 1001-1008 (2014)

33. M. Shaaban, J. Scheffran, Selection of sustainable development indicators for the assessment of electricity production in Egypt, Sustain. Energy Technol. Assess. 22, 65-73 (2017)

34. F. Cucchiella, I. D'Adamo, M. Gastaldi, S.L. Koh, P. Rosa, A comparison of environmental and energetic performance of European countries: a sustainability index, Renew. Sustain. Energy Rev. 78, 401-413 (2017)

35. S. Zeng, D. Streimikiene, T. Baležentis, Review of and comparative assessment of energy security in Baltic States, Renew. Sustain. Energy Rev. 76, 185-192 (2017)

36. I. Iddrisu, S.C. Bhattacharyya, Sustainable Energy Development Index: A multi-dimensional indicator for measuring sustainable energy development, Renew. Sustain. Energy Rev. 50, 513-530 (2015)

37. S. Luthra, S.K. Mangla, R.K. Kharb, Sustainable assessment in energy planning and management in Indian perspective, Renew. Sustain. Energy Rev. 47, 58-73 (2015)

38. B. Anna, Classification of the European Union member states according to the relative level of sustainable development, Qual. Quant. 50, 2591-2605 (2016)

39. M. Urbaniec, Sustainable development indicators in Poland: measurement and system evaluation, Entrep. Bus. Econ. Rev. 3, 119-134 (2015)

40. R. Ritchie, O.-O. Mispy, Measuring progress towards the Sustainable Development Goals, SDG-Tracker.org, 2018

41. United Nations General Assembly, Global indicator framework for the Sustainable Development Goals and targets of the 2030 Agenda for Sustainable Development, 2020

42. D.S. Kourkoumpas, G. Benekos, N. Nikolopoulos, S. Karellas, P. Grammelis, E. Kakaras, A review of key environmental and energy performance indicators for the case of renewable energy systems when integrated with storage solutions, Appl. Energy. 231, 380-398 (2018)

43. Y.W. Pratama et al., Multi-objective optimization of a multiregional electricity system in an archipelagic state: the role of renewable energy in energy system sustainability, Renew. Sustain. Energy Rev. 77, 423-439 (2017)

44. M.A. Cuesta, T. Castillo-Calzadilla, C.E. Borges, A critical analysis on hybrid renewable energy modeling tools: an emerging opportunity to include social indicators to optimise systems in small communities, Renew. Sustain. Energy Rev. 122, 109691 (2020)

45. F.E. Boran, A new approach for evaluation of renewable energy resources: a case of Turkey, Energy Sources, Part B Econ. Plan. Policy. 13, 196-204 (2018) 
46. M. Ligus, Evaluation of economic, social and environmental effects of low-emission energy technologies development in poland: a multi-criteria analysis with application of a Fuzzy Analytic Hierarchy Process (FAHP), Energies 10, 1550 (2017)

47. Z.Y. Zhao, Y.L. Chen, Critical factors affecting the development of renewable energy power generation: evidence from China, J. Clean. Prod. 184, 466-480 (2018)

48. B. Atilgan, A. Azapagic, An integrated life cycle sustainability assessment of electricity generation in Turkey, Energy Policy 93, 168-186 (2016)

49. H. Al Garni, A. Kassem, A. Awasthi, D. Komljenovic, K. AlHaddad, A multicriteria decision making approach for evaluating renewable power generation sources in Saudi Arabia, Sustain. Energy Technol. Assess. 16,137-150 (2016)

50. T. Ertay, C. Kahraman, I. Kaya, Evaluation of renewable energy alternatives using MACBETH and fuzzy AHP multicriteria methods: the case of Turkey, Technol. Econ. Dev. Econ. 19, 38-62 (2013)

51. D. Connolly, H. Lund, B.V. Mathiesen, M. Leahy, A review of computer tools for analysing the integration of renewable energy into various energy systems, Appl. Energy. 87, 1059-1082 (2010)

52. H.K. Ringkjøb, P.M. Haugan, I.M. Solbrekke, A review of modelling tools for energy and electricity systems with large shares of variable renewables, Renew. Sustain. Energy Rev. 9, 440-459 (2018)

53. A. Evans, V. Strezov, T.J. Evans, Assessment of sustainability indicators for renewable energy technologies, Renew. Sustain. Energy Rev. 13, 1082-1088 (2009)
54. F. Unander, Energy indicators and sustainable development: the International Energy Agency approach, Nat. Resour. Forum. 29, 377-391 (2005)

55. K. Moustakas, M. Loizidou, M. Rehan, A.S. Nizami, A review of recent developments in renewable and sustainable energy systems: key challenges and future perspective, Renew. Sustain. Energy Rev. 119, 109418 (2020)

56. Varun, R. Prakash, I.K. Bhat, Energy, economics and environmental impacts of renewable energy systems, Renew. Sustain. Energy Rev. 13, 2716-2721 (2009)

57. A. Kumar et al., A review of multi criteria decision making (MCDM) towards sustainable renewable energy development, Renew. Sustain. Energy Rev. 69, 596-609 (2017)

58. M. Collotta, P. Champagne, G. Tomasoni, M. Alberti, L. Busi, W. Mabee, Critical indicators of sustainability for biofuels: an analysis through a life cycle sustainability assessment perspective, Renew. Sustain. Energy Rev. 115, 109358 (2019)

59. V. Campos-Guzmán, M.S. García-Cáscales, N. Espinosa, A. Urbina, Life cycle analysis with multi-criteria decision making: a review of approaches for the sustainability evaluation of renewable energy technologies, Renew. Sustain. Energy Rev. 104, 343-366 (2019)

60. M. Shahbaz, C. Raghutla, K.R. Chittedi, Z. Jiao, X.V. Vo, The effect of renewable energy consumption on economic growth: evidence from the renewable energy country attractive index, Energy 207, 118162 (2020)

61. B. Popović, S. Janković Šoja, T. Paunović, R. Maletić, Evaluation of sustainable development management in EU countries, Sustainability 11, 7140 (2019)

62. L. Tran, An interactive method to select a set of sustainable urban development indicators, Ecol. Indic. 61, 418-427 (2016)

Cite this article as: Shoeib Faraji Abdolmaleki, Pastora M. Bello Bugallo, Evaluation of Renewable Energy System For Sustainable Development, Renew. Energy Environ. Sustain. 6, 44 (2021) 